(a) (1) https://creativecommons.org/licenses/by/4.0/

ARTIGO

\title{
AUTOEFICÁCIA MATEMÁTICA E MOTIVAÇÃO PARA APRENDER NA FORMAÇÃO INICIAL DE PEDAGOGOS
}

\author{
JUCILEIDE DAS DORES LUCAS TOLENTINO ${ }^{1}$ \\ http://orcid.org/0000-0003-1473-3945 \\ ANA CRISTINA FERREIRA ${ }^{2}$ \\ http://orcid.org/0000-0003-0953-1468 \\ EDMILSON MINORU TORISU 3 \\ https://orcid.org/0000-0001-7383-387X
}

\begin{abstract}
RESUMO: As crenças dos professores sobre sua própria capacidade de aprender Matemática podem influenciar a forma como se relacionam com essa disciplina, afetando tanto sua aprendizagem quanto a de seus alunos. Contudo, a relação que muitos futuros professores dos anos iniciais, estudantes de Pedagogia, estabelecem com a Matemática não é das mais positivas. No presente artigo, analisamos possíveis relações entre as crenças de autoeficácia matemática de um grupo de licenciandas em Pedagogia e sua motivação para aprender Matemática. $\mathrm{O}$ estudo se fundamentou nas noções de motivação para aprender e autoeficácia da Teoria Social Cognitiva. A metodologia, de abordagem qualitativa, envolveu uma pesquisa de intervenção da qual participaram oito licenciandas em Pedagogia de uma universidade pública do interior de Minas Gerais. Os dados foram produzidos por meio da observação de aulas de duas disciplinas de Matemática do referido curso, durante dois semestres, bem como de reuniões de um grupo de estudos constituído pela pesquisadora principal e as oito licenciandas; registros produzidos pelas participantes do estudo e questionário respondido pelas mesmas. Os resultados evidenciam que, após a intervenção, houve o fortalecimento das crenças de autoeficácia associados principalmente ao aumento da frequência de experiências de sucesso, além do desenvolvimento de uma relação mais favorável para a aprendizagem de Matemática. Além disso, há fortes indícios de aumento da motivação para aprender Matemática.
\end{abstract}

Palavras-chave: Educação Matemática, motivação para aprender, autoeficácia matemática, licenciatura em Pedagogia..

\section{MATHEMATICS SELF-EFFICACY AND MOTIVATION TO LEARN IN INITIAL TEACHER EDUCATION}

ABSTRACT: Teachers' beliefs about their own ability to learn mathematics can influence how they relate to this subject, affecting both their learning and that of their students. However, the relationship that many future teachers of the early years, students of Pedagogy, establish with mathematics is not the

\footnotetext{
${ }^{1}$ Universidade Federal de Ouro Preto (UFOP). Ouro Preto, MG, Brasil. <lucasjucileide@gmail.com>

${ }^{2}$ Universidade Federal de Ouro Preto (UFOP). Ouro Preto, MG, Brasil. < anacf@ufop.edu.br>

${ }^{3}$ Universidade Federal de Ouro Preto (UFOP). Ouro Preto, MG, Brasil. <edmilson@ufop.edu.br> Educação em Revista|Belo Horizonte|v.36|e227158|2020
} 
most positive. In the present article, we analyze possible relationships between the mathematics selfefficacy of a group of Pedagogy graduates and their motivation to learn Mathematics. The study was based on the notions of motivation to learn and self-efficacy of the Cognitive Social Theory. The methodology, with a qualitative approach, involved an intervention research involving eight undergraduate students in Pedagogy at a public university of Minas Gerais (Brazil). The data were produced by observing two Mathematics classes of the course during two semesters, as well as in meetings of a study group including the principal researcher and the eight undergraduate students; records produced by the study participants and a questionnaire answered by them. The results show the influence of this research to the strengthening of self-efficacy beliefs associated mainly with the increased frequency of successful experiences, as well as the development of a more favorable relationship for learning mathematics. In addition, there is strong evidence of increased motivation to learn mathematics.

Keywords: Mathematics education, motivation to learn, Mathematics self-efficacy, Pedagogy course.

\section{AUTOEFICACIA MATEMÁTICA Y MOTIVACIÓN PARA APRENDER EN LAFORMACIÓN INICIAL DE PEDAGOGOS}

RESÚMEN: Las creencias de los maestros acerca de su propia capacidad para aprender matemáticas pueden influir en la forma como se relacionan con esta disciplina, afectando tanto su aprendizaje como el de sus estudiantes. Sin embargo, la relación que muchos futuros maestros, estudiantes de Pedagogía, establecen con las matemáticas no es la más positiva. En el presente artículo, analizamos las posibles relaciones entre las creencias de autoeficacia matemática de un grupo de estudiantes de Pedagogía y su motivación para aprender Matemáticas. El estudio se basó en las nociones de motivación para aprender y autoeficacia de la Teoría Social Cognitiva. La metodología, de enfoque cualitativo, se dio por medio de una investigación de intervención desarollada con ocho estudiantes de Pedagogía de una universidad pública de Minas Gerais (Brazil). Los datos se produjeron a lo largo de dos semestres lectivos mediante: observación de dos asignaturas de matemáticas y de las reuniones de un grupo de estudio compuesto por la investigadora principal y las ocho estudiantes de Pedagogía; registros producidos por los participantes del estudio; y un cuestionario respondido por ellos. Los resultados muestran la influencia del estúdio en el fortalecimiento de las creencias de autoeficacia asociadas principalmente con la mayor frecuencia de experiencias exitosas, así como el desarrollo de una relación más favorable para el aprendizaje de las matemáticas. Además, existe una fuerte evidencia de mayor motivación para aprender matemáticas.

Palabras clave: Educación Matemática, motivación para aprender, creencias de autoeficacia matemática, formación inicial de maestros. 


\section{INTRODUÇÃO}

A formação dos professores para atuar nos anos iniciais da escolarização nem sempre foi atribuída ao curso de Pedagogia. A história desse curso no Brasil evidencia que, inicialmente, o trabalho com disciplinas específicas não compunha sua matriz curricular. Até a década de 1960, o curso não tinha por objetivo a formação de professores para a Educação Infantil e os anos iniciais do Ensino Fundamental, mas sim de "técnicos" ou "especialistas" em Educação bem como professores para atuarem com as disciplinas pedagógicas nas Escolas Normais (BAUMANN; BICUDO, 2010). A formação dos professores se dava, principalmente, nas Escolas Normais ${ }^{4}$, em cursos de nível médio (antigo $2^{\circ}$ grau).

Apenas no início da década de 1970, os habilitados em Pedagogia receberam a autorização para exercer a docência em todas as disciplinas do ensino primário (atualmente, anos iniciais do Ensino Fundamental), inclusive Matemática. Apesar do direito concedido, não havia, nos cursos de Pedagogia, disciplinas que explorassem os conteúdos específicos. Nesse primeiro momento, foi incorporada apenas uma disciplina cujo foco era a docência nos primeiros anos de escolarização.

A partir da década de 1980, o movimento nacional de formação de professores intensifica a defesa da "docência como base da formação e da identidade de todo educador" (BAUMANN; BICUDO, 2010, p. 186), destacando que a "base e identidade do pedagogo, consequentemente, a do curso de Pedagogia, é a docência nos anos iniciais do Ensino Fundamental e na Educação Infantil” (BAUMANN; BICUDO, 2010, p. 186).

A proposta defendida por esse movimento foi consolidada com a Resolução CNE/CP $\mathrm{n}^{\circ}$ 1/2006. Segundo o artigo $4^{\circ}$ dessa resolução:

O curso de Licenciatura em Pedagogia destina-se à formação de professores para exercer funções de magistério na Educação Infantil e nos anos iniciais do Ensino Fundamental, nos cursos de Ensino Médio, na modalidade Normal, de Educação Profissional na área de serviços e apoio escolar e em outras áreas nas quais sejam previstos conhecimentos pedagógicos (BRASIL, 2006, p. 2).

Nesse sentido, o egresso do curso de Pedagogia deve estar apto a ensinar Matemática, Português, Ciências, História, Geografia e Artes, de forma interdisciplinar e adequada às diferentes fases do desenvolvimento humano.

Em seu estudo, Souto (2016) analisou os projetos Pedagógicos de dois cursos de Pedagogia de instituições de Ensino Superior do Estado de Minas Gerais e encontrou que, embora ambos os cursos ofereçam um número de disciplinas Matemáticas superior ao usualmente previsto nos cursos de Pedagogia brasileiros, elas não parecem suficientes para que os futuros pedagogos se sintam seguros para lecionar essa disciplina. Durante a coleta de dados, os licenciandos dos cursos investigados relataram problemas na sua formação matemática, seja pela falta de uma compreensão do conteúdo ensinado e de como ensiná-lo, seja por acreditarem que se aprende a ensinar é na prática. Os resultados encontrados evidenciaram que é necessário mudar a maneira como a formação matemática do pedagogo vem sendo realizada. Para que os futuros pedagogos se sintam confortáveis com a possibilidade de lecionar essa

\footnotetext{
${ }^{4}$ A primeira escola normal brasileira foi criada no Rio de Janeiro (então a capital do país), em 1835. Nesse mesmo ano, foi criada uma escola normal em Minas Gerais (instalada em 1840) e, nos anos seguintes, outras foram criadas em várias outras províncias brasileiras. Tais escolas foram responsáveis pela formação dos professores das séries iniciais até 1970. Durante esse período, passaram por diversos processos de reformulação na expectativa de unificar e melhorar a formação docente. Em 1971, a Lei 5692 estabelece diretrizes e bases para o primeiro e segundo graus e também para a escola normal, que se torna Habilitação Específica para o Magistério. O agravamento das condições da formação de professores, em nível nacional, atrelado à desvalorização profissional e ao baixo número de matrículas nestas instituições, levou às propostas de "revitalização das escolas normais". Em 1982, o MEC propõe a criação dos Centros de Formação e Aperfeiçoamento do Magistério (CEFAM), cujo objetivo era criar condições para que as escolas normais oferecessem formação técnica e política aos futuros professores da educação pré-escolar e dos anos iniciais. Em 1996, a Lei 9394 determina que a formação de docentes para atuar na Educação Básica deveria ocorrer em nível superior, em curso de graduação na modalidade licenciatura (TANURI, 2000).
} 
disciplina, "muito mais do que focar na questão da carga horária é preciso repensar a forma como as disciplinas matemáticas são desenvolvidas" (SOUTO, 2016, p. 97).

Tais resultados corroboram os achados de pesquisas anteriores. Carzola e Santana (2005), por exemplo, ao analisarem concepções, atitudes e crenças em relação à Matemática na formação do professor dos anos iniciais da Educação Básica, verificaram que, dos 119 participantes da pesquisa, quase um terço declarou não gostar da Matemática e cerca de um quarto afirmou que poucos de seus alunos gostam de Matemática. Contudo, o desenvolvimento de atitudes favoráveis com relação à Matemática é particularmente importante para professores desse nível de ensino, pois são eles que iniciarão a formação matemática das crianças, favorecendo (ou não) sua relação afetiva com essa disciplina (CARZOLA e SANTANA, 2005).

Muitos alunos ingressantes no curso de Pedagogia costumam trazer crenças e atitudes negativas em relação à Matemática e seu ensino. Tal relação, em boa medida, advém de fracassos escolares recorrentes e da concepção de que a Matemática só pode ser compreendida por algumas pessoas. A protelação desse problema, além de prejudicar a formação deste aluno, acabará afetando a sua futura prática docente (FIORENTINI, 2008). Também "a carga horária reduzida que os cursos de Pedagogia têm destinado para a formação conceitual e didático-pedagógica da Matemática tem sido um problema crônico e não contemplado pelas diretrizes Curriculares" (FIORENTINI, 2008, p. 56).

Todo o exposto reforça a necessidade de se repensar a formação matemática do professor que atuará na Educação Infantil e Anos Iniciais do Ensino Fundamental, de modo que ele seja capaz de mediar a construção de conhecimentos matemáticos por parte das crianças, bem como de favorecer o desenvolvimento de uma relação positiva com essa disciplina.

No presente artigo, apresentamos um recorte de uma pesquisa de Mestrado ${ }^{5}$ (TOLENTINO, 2018), cujo principal objetivo foi investigar como a participação de estudantes do curso de Pedagogia (presencial) de uma instituição federal do interior de Minas Gerais em um grupo de estudos voltado para o desenvolvimento da aprendizagem autorregulada e para a construção de conhecimentos matemáticos influencia sua motivação para aprender e ensinar essa disciplina. A análise se deu a partir de três eixos. No primeiro, abordamos o engajamento das alunas nas tarefas matemáticas realizadas no grupo de estudos e na sala de aula, buscando compará-lo, em alguma medida, com o comportamento usual das mesmas antes de iniciarem sua participação no grupo. Da mesma forma, no segundo eixo, focalizamos as crenças de autoeficácia, procurando indícios de fortalecimento. Por fim, no terceiro eixo, nos detemos na dinâmica do grupo de estudos e suas contribuições para a motivação para aprender Matemática.

Procuramos, neste artigo, aprofundar a discussão realizada no segundo eixo, investigando possíveis relações entre a autoeficácia matemática e a motivação para aprender essa disciplina, por parte das participantes do grupo de estudos. Para isso, situamos teoricamente as noções de motivação para aprender e autoeficácia matemática. Em seguida, descrevemos as opções metodológicas adotadas e passamos à análise dos dados produzidos. Encerramos com algumas reflexões acerca do processo.

\section{MOTIVAÇÃO PARA APRENDER E CRENÇAS DE AUTOEFICÁCIA MATEMÁTICA}

Entendemos a motivação para aprender da mesma forma que Brophy (1987), ou seja, como uma disposição duradoura que leva o aluno a esforçar-se para aprender determinado conteúdo, em uma situação de aprendizagem. Assim, a motivação para aprender existe quando o engajamento do aluno é guiado pela intenção de adquirir o conhecimento que a atividade propõe ensinar (BROPHY, 1987).

Como Reeve (2011, p.4), entendemos que "o estudo da motivação se refere aos processos que fornecem ao comportamento sua energia e direção". A direção significa que o comportamento tem um propósito, ou seja, é direcionado para alcançar um resultado. Os processos que direcionam o

\footnotetext{
${ }^{5}$ A questão de investigação que norteou a pesquisa de Mestrado foi: Como a participação em um grupo de estudos voltado para a aprendizagem autorregulada e para a construção de conhecimentos matemáticos influencia a motivação para aprender Matemática em alunos de um curso de Pedagogia?

Educação em Revista|Belo Horizonte|v.36|e227158|2020
} 
comportamento de um indivíduo emanam tanto de suas forças internas quanto do seu ambiente. Sendo assim, os motivos podem ser internos ou externos.

Uma das crenças motivacionais mais importantes para o desenvolvimento do aluno é a autoeficácia, que se refere "à percepção da capacidade para realização de uma tarefa específica ou de um conjunto de tarefas em um domínio específico" (BANDURA, 1986 e 1987 apud AZZI e POLYDORO, 2010, p.128).

Estudantes com crenças de autoeficácia positivas, isto é, que acreditam que são capazes de executar determinada tarefa, geralmente se esforçam mais para desenvolvê-las e são mais persistentes diante dos obstáculos (LINNENBRINK e PINTRICH, 2002).

Quando as pessoas acreditam que suas ações podem levar aos resultados que almejam, elas ficam estimuladas a agir e a superar suas dificuldades. Porém, Pajares e Valiente (2006 apud AZZI e POLYDORO, 2010), destacam que as crenças de autoeficácia não são capazes de produzir sucesso em situações nas quais as habilidades e os conhecimentos necessários para a realização da tarefa estão ausentes. $\mathrm{O}$ indivíduo deve reconhecer suas habilidades reais, não superestimando ou subestimando suas capacidades. Ele deve se manter otimista, dentro de suas potencialidades.

As crenças de autoeficácia destacam-se na Teoria Social Cognitiva de Albert Bandura. Nessa teoria, o autodesenvolvimento e a mudança de comportamento são fundamentados na perspectiva da agência. Ser agente significa agir de forma intencional para mudar o curso dos acontecimentos. Tudo funciona como se o indivíduo possuísse uma margem de manobra para suas ações, realizando "coisas que lhes dão satisfação e um sentido de amor próprio, abstendo-se de atos que levem à autocensura" (BANDURA, 2008, p. 15).

Há vários mecanismos para que uma pessoa exerça sua agência, mas nenhum é mais central que as crenças de autoeficácia (BANDURA, 2008). De acordo com esse autor:

\begin{abstract}
As crenças de autoeficácia são a base da agência humana. A menos que as pessoas acreditem que podem produzir os resultados que desejam e prevenir os resultados prejudiciais por meio de seus atos, elas terão pouco incentivo para agir ou perseverar frente a dificuldades. [...] Elas se baseiam na crença básica de que é preciso ter poder para produzir efeitos por meio das próprias ações (BANDURA, 2008, p. 78).
\end{abstract}

De todo o exposto, depreendemos que as crenças de autoeficácia influenciam diretamente a capacidade de agência humana e, por consequência, a motivação para aprender. A origem etimológica da palavra motivação vem do latim, movere, que se relaciona com o substantivo motivum. Dessa forma, podemos compreender motivação como "aquilo que move uma pessoa ou a põe em ação ou a faz mudar de curso" (BZUNECK, 2009a, p. 9). Assim, a crença do indivíduo em sua capacidade de desenvolver ou não uma tarefa certamente influenciará a sua ação (RODRIGUES, 2015). Em função dos julgamentos de autoeficácia, a pessoa decide uma direção para suas ações e antecipa o que fazer para alcançar seus objetivos.

As crenças de autoeficácia influenciam pessoas em ambientes diversos. No ambiente escolar, estudantes com altas crenças de autoeficácia mantêm o esforço para realizar as tarefas desde o início e ao longo de todo o processo, de maneira persistente, mesmo que sobrevenham dificuldades (BZUNECK, 2009b). No caso dos professores, que aqui nos interessa em particular, de acordo com Bzuneck (2000), altas crenças de eficácia dos professores podem possibilitar melhor desempenho dos alunos, em diversas disciplinas focalizadas, incrementar as crenças de autoeficácia dos próprios alunos, consideradas como variável determinante de sua motivação, e incentivar a adoção de estratégias mais adequadas de lidar com os alunos, especialmente com alunos-problema.

No ambiente escolar, a Matemática, muitas vezes, é uma disciplina temida pelos alunos que consideram que sua aprendizagem se reserva a pessoas mais capazes. As relações afetivas estabelecidas por muitos discentes com seu conteúdo remetem a sentimentos negativos e à falta de confiança em suas habilidades, o que acaba levando a situações de fracasso. Como Torisu (2010, p. 51), entendemos que:

Em qualquer nível, discutir a autoeficácia matemática dos estudantes pode nos revelar muito, acerca de como eles vêm se relacionando com essa disciplina. Os resultados podem dar indícios 
da necessidade, muitas vezes iminente, de alterações da prática pedagógica, ou de como certa prática pode contribuir para o incremento e manutenção das crenças de autoeficácia nos estudantes.

Entendemos que autoeficácia matemática compreende a percepção do indivíduo sobre a própria capacidade para lidar com as situações que envolvem os temas de domínio matemático. Assim como Rodrigues (2015), consideramos que essa percepção pode variar de acordo com os conteúdos abordados e também com o contexto situacional.

Sendo as crenças de autoeficácia tão importantes no processo educativo, tanto no que se refere à motivação de estudantes quanto de professores, como elas surgem? Quais são suas fontes? De acordo com a Teoria Social Cognitiva, as principais fontes são: as experiências de êxito, experiências vicárias, persuasão verbal e estados fisiológicos.

As experiências de êxito (ou experiências de domínio) dizem respeito às vivências pessoais. Quando a pessoa alcança o sucesso, ela cria expectativas sobre o seu bom desempenho em tarefas futuras. De forma similar, situações de fracasso podem fragilizar suas crenças de autoeficácia. Por isso, é importante que o professor proporcione tarefas condizentes com o conteúdo estudado e com o estágio cognitivo de seus alunos (RODRIGUES, 2015).

Experiências vicárias são adquiridas pela observação de pares que possuem características similares às do observador. $\mathrm{O}$ êxito de um colega de classe com características semelhantes pode levar um aluno a desenvolver um comportamento similar ao de seu colega na expectativa de também alcançar o sucesso (RODRIGUES, 2015).

A persuasão verbal consiste na exaltação verbal das nossas capacidades por alguém que nos é estimado. Quando uma pessoa que consideramos ter credibilidade nos incentiva, reforça nossas capacidades e nos sentimos mais capazes e encorajados para desenvolver as tarefas. Rodrigues (2015) chama a atenção para o fato de que a indução de crenças falsas sobre as competências pode ter efeitos negativos, pois, geralmente, elas não serão confirmadas pela experiência pessoal, deixando em descrédito o persuasor.

Os estados fisiológicos são as interferências dos indicadores emocionais ou afetivos nas percepções de autoeficácia. Situações de cansaço, estresse, humor, ansiedade podem influenciar o grau de confiança do indivíduo em suas habilidades e comprometer seu desempenho. O estado afetivo também influencia a seleção de memórias e o julgamento das avaliações que a pessoa faz sobre elas. $\mathrm{O}$ indivíduo avalia suas lembranças utilizando a sua percepção das reações afetivas em vez das informações recordadas. Uma maneira de aumentar as crenças de autoeficácia é promover o bem-estar emocional dos indivíduos. $\mathrm{Na}$ sala de aula, o professor deve criar um ambiente agradável, onde o aluno se sinta confortável para participar das atividades (RODRIGUES, 2015).

Todas as fontes de autoeficácia dependem da interpretação pessoal das informações e os seus efeitos dependem de como cada indivíduo as aprecia cognitivamente (RODRIGUES, 2015).

A escola tem um grande papel na validação da capacidade cognitiva das pessoas, por ser um lugar onde as habilidades e conhecimentos são avaliados e comparados. Fatores como a interpretação dos professores sobre as situações de sucesso e fracasso dos alunos, bem como a comparação entre eles podem refletir em seu senso de autoeficácia (RODRIGUES, 2015).

Ao propor um ambiente agradável, de confiança mútua, onde os alunos percebam sua capacidade para desenvolver as atividades, o professor possibilita o desenvolvimento de crenças de autoeficácia robustas pelos discentes. "Se robustas, as crenças de autoeficácia levam a uma maior motivação do aluno diante de uma tarefa, fazendo com que ele dedique maior tempo a ela e transponha, com maior facilidade, os obstáculos que lhe aparecerem" (TORISU e FERREIRA, 2009, p. 169).

As crenças dos professores sobre sua própria capacidade também podem influenciar a aprendizagem de seus alunos. Professores com percepções de autoeficácia mais elevadas se envolvem mais com seu trabalho, se comprometem com a organização das atividades e demonstram maior entusiasmo na sala de aula, o que reflete positivamente em sua forma de ensinar (FERREIRA, 2018).

A abordagem dada às atividades matemáticas durante as aulas pode tornar mais evidente a questão da capacidade, gerando, muitas vezes, ideias como "não consigo aprender este conteúdo". Por 
isso, é necessário que o professor e a escola como um todo ofereçam ao aluno condições para que ele possa manter/desenvolver crenças de autoeficácia robustas. Alunos com percepções positivas sobre suas capacidades são mais motivados a aprender.

\section{METODOLOGIA}

Dada a natureza de nossa questão de investigação, optamos pela abordagem qualitativa para a pesquisa. Tal abordagem se ocupa, dentro do campo das Ciências Sociais, de uma realidade que não pode ou não deve ser quantificada, pois trabalha com significados, atitudes, crenças, e tem como objeto de estudo o universo das produções humanas, que pode ser resumido no mundo das relações, das representações e da intencionalidade (MINAYO, 2009a).

A pesquisa de Mestrado a partir da qual o presente artigo foi construído foi aprovada pelo Comitê de Ética em Pesquisa da $\mathrm{UFOP}^{6}$ e foi estruturada e desenvolvida de modo a preservar o anonimato das participantes. Todas assinaram um Termo de Consentimento Livre e Esclarecido e, dentre outras coisas, foram informadas de que nada as obrigaria a manter seu consentimento em participar da pesquisa, ou seja, poderiam decidir, em qualquer momento, deixar de participar do grupo de estudos ou seguir participando, mas não autorizar o uso de suas informações para a pesquisa. Adotamos um pseudônimo para cada uma delas. Além disso, a participação no grupo de estudos era voluntária, não acrescentando pontos à suas notas na disciplina de Matemática.

Ressaltamos que analisar o grupo de estudos como um todo é uma tarefa difícil, dada a diversidade dos sujeitos que o integravam. Embora todas as participantes fossem alunas de uma mesma disciplina do curso de Pedagogia, cada uma delas tinha seus objetivos, suas limitações e suas próprias percepções em relação à Matemática. Isso influenciou a forma como os encontros eram organizados e demandou muito esforço em seu planejamento.

Em nossa pesquisa de Mestrado, a análise foi estruturada a partir da leitura cuidadosa de todos os dados produzidos ao longo do estudo, e de sua interpretação à luz do referencial teórico que fundamentou a pesquisa. Nesse sentido, organizamos em três eixos as contribuições advindas da participação no grupo sobre a motivação para aprender Matemática: engajamento nas atividades, crenças de autoeficácia e dinâmica de trabalho no grupo de estudos. Discutimos, neste artigo, o eixo das crenças de autoeficácia, que aborda como a autoeficácia matemática das alunas se aprimora (ou se torna mais robusta) ao longo de sua participação no grupo de estudos, e como isso se relaciona com a motivação para aprender.

\section{Contexto e participantes da pesquisa}

A pesquisa foi desenvolvida com alunos do curso presencial de Pedagogia de uma instituição federal do interior de Minas Gerais, escolhida devido à sua proximidade das residências das pesquisadoras.

O curso de Pedagogia - contexto da presente pesquisa - oferece vagas nos períodos vespertinos e noturnos, e recebe alunos de diversas regiões e faixas etárias. Alguns desses alunos já possuíam experiência como professores da Educação Básica, seja nos anos iniciais, seja nos anos finais do Ensino Fundamental.

Dos 37 alunos que inicialmente manifestaram interesse em participar da pesquisa, seis tinham disponibilidade para participar dos encontros de um grupo de estudos de Matemática, que se reunia semanalmente, em dia e horário combinados coletivamente. Todas eram do sexo feminino, com idade entre 18 e 30 anos e sem experiência docente. Acompanhamos essas alunas durante os semestres letivos de 2017/1 e 2017/2, tanto nos encontros do grupo quanto nas aulas das disciplinas de Matemática.

No segundo semestre de 2017, uma das alunas deixou de participar dos encontros do grupo de estudos e recebemos três novos membros (todas do sexo feminino e da mesma faixa etária que as

${ }^{6}$ CAAE: 6007.1416.8.0000.5150

Educação em Revista|Belo Horizonte|v.36|e227158|2020 
demais participantes). Assim, o grupo de estudos foi composto por seis alunas, no primeiro semestre de 2017, e por oito, no semestre seguinte. Atribuímos nomes fictícios para as participantes. Assim, no $1^{\circ}$ semestre de 2017, participaram Ana, Bia, Karol, Lúcia, Maria e Teresa e, no $2^{\circ}$ semestre daquele ano, Ana deixou de participar do grupo de estudos, e Clara, Duda e Alice foram incluídas.

Inicialmente, as alunas participantes do grupo de estudos não tinham muito contato umas com as outras. Somente Karol, Maria e Teresa sentavam-se próximas durante as aulas. Lúcia e Alice pareciam mais tímidas. Geralmente, conversavam pouco com os colegas da classe. Duda e Clara, embora não fossem tão acanhadas quanto Lúcia e Alice, também não se enturmavam muito. Conversavam com um grupo restrito de colegas, perto dos quais se sentavam. Bia era a única que, como ela mesma se descreveu, era comunicativa e expressava bem seus sentimentos, tanto nos encontros do grupo de estudos quanto nas aulas de Matemática.

Pelos relatos das alunas durante as aulas, grupo de estudos e resposta aos instrumentos, percebemos que a maioria delas possuía dificuldade para aprender Matemática e já havia experimentado sentimentos negativos com relação a essa disciplina.

O trabalho iniciou-se com a observação das aulas da disciplina Matemática: Conteúdos e Metodologias I. Posteriormente, criamos um grupo de estudos em horário extraclasse. Na primeira fase da pesquisa $\left(1^{\circ}\right.$ semestre de 2017), foram realizados nove encontros de cerca de 1 hora cada. Na segunda fase ( $2^{\circ}$ semestre de 2017), continuamos acompanhando as alunas na disciplina Matemática: Conteúdos e Metodologias II, e realizamos 19 encontros do grupo.

Nesses encontros, procuramos desenvolver atividades que, de alguma forma, também contribuíssem para o fortalecimento das crenças de autoeficácia matemática, buscando ampliar seus conhecimentos matemáticos, mas também favorecendo uma aprendizagem autorregulada. As atividades realizadas nos encontros pautavam-se pelos conteúdos desenvolvidos em sala de aula, na disciplina de Matemática, e davam atenção especial aos tópicos que geravam maior dificuldade.

A dinâmica dos encontros, geralmente, contava com três momentos: um momento inicial, no qual trabalhávamos com as dúvidas e dificuldades apontadas pelas alunas sobre conteúdos abordados nas aulas de Matemática; um segundo, no qual propúnhamos tarefas matemáticas (também relacionadas aos conteúdos previstos para a disciplina); e o terceiro, um momento de reflexão sobre o processo de aprendizagem das participantes?

\section{A produção de dados}

Investigar a motivação para aprender Matemática e crenças de autoeficácia implica desafios do ponto de vista metodológico, uma vez que envolve aspectos mais subjetivos relativos à forma como cada indivíduo percebe, interpreta e lida com a aprendizagem dessa disciplina. Dessa forma, torna-se necessário buscar elementos presentes no comportamento, nas atitudes, expressões orais e escritas, e nos relatos dos participantes da pesquisa.

A produção de dados aconteceu ao longo de todo o trabalho de campo (23/02/2017 a 15/02/18), por meio de vários instrumentos. Utilizamos: diário de campo da pesquisadora, registro de dados produzidos pelos alunos, gravações em áudio e vídeo, entrevistas e questionário.

Ao longo do trabalho de campo, analisamos tanto as atividades produzidas pelos alunos em folhas impressas, distribuídas pelo professor, como as desenvolvidas por eles no caderno específico para as atividades do grupo de estudos. As atividades visavam explorar os conteúdos matemáticos pertencentes ao programa da disciplina, bem como sentimentos em relação à Matemática.

Todos os encontros do grupo de estudos foram gravados em áudio e, alguns deles, também em vídeo. Também foram realizadas gravações em áudio de algumas aulas. O objetivo dessas gravações foi resgatar as expressões orais e gestuais dos participantes da pesquisa, além das falas. Todas as gravações em áudio do grupo de estudos foram transcritas.

No dia 29/01/18, realizamos uma entrevista, buscando compreender os comportamentos e ações demonstrados pelas alunas, durante as aulas e no grupo de estudos. Também realizamos, em alguns

\footnotetext{
${ }^{7}$ Ver mais detalhes em Tolentino (2018).
} 
momentos dos encontros, entrevistas informais ${ }^{8}$. O primeiro questionário foi proposto às alunas no dia 26/05/2017, com a finalidade de identificar como elas se relacionavam com a Matemática e o que pensavam sobre sua aprendizagem nessa disciplina. Nesse instrumento, utilizamos questões abertas e fechadas. O segundo questionário, também composto por questões abertas e fechadas, foi proposto no dia 18/01/18, com o intuito de perceber as influências do grupo de estudos no processo de ensino e aprendizagem de seus participantes.

Optamos por transcrever os diálogos de forma fiel e, em vários momentos, trazemos episódios inteiros, de forma a evitar que sejam retiradas de contexto as afirmações feitas. Na maioria dos relatos, sublinhamos os aspectos que mais nos chamaram a atenção, diante do eixo analisado.

\section{AUTOEFICÁCIA MATEMÁTICA E A MOTIVAÇÃO PARA APRENDER ESSA DISCIPLINA: ALGUNS ACHADOS}

Durante o acompanhamento das aulas e a realização dos encontros do grupo de estudos, percebemos que, inicialmente, as respostas e atitudes das alunas apontavam para crenças de autoeficácia matemática frágeis. Algumas participantes não pareciam confiantes em sua capacidade para resolver as atividades solicitadas durante os encontros e as aulas.

Destacamos, a seguir, um episódio sobre a resolução de problemas envolvendo situações aditivas. Neste encontro, Bia se mostra insegura quanto a sua capacidade para resolver as tarefas.

Problema 1: Lucas e Ricardo colecionam chaveiros há vários anos. Descubra quantos chaveiros tem Lucas a partir de duas pistas: Ricardo tem 227 chaveiros a menos que Lucas, e, no total, sua coleção conta com 815 chaveiros.

Problema 2: Pedro e Jucileide estão jogando Bafo. Sabendo que Pedro perdeu 231 figurinhas no decorrer do jogo e terminou com 190, quantas figurinhas ele possuía no início do jogo?

Problema 3: João gosta de jogar videogames no computador. Em cada fase do jogo, ele precisa reunir uma quantidade de pontos para saber se subirá para um nível mais avançado ou não. Se ele iniciou a segunda fase de um jogo com uma certa quantidade de pontos, perdeu 1542 pontos e depois ganhou 2003 pontos, qual foi seu saldo ao final?

Pedi que elas os resolvessem, utilizando as dicas apresentadas na ficha de apoio.

Bia questionou se era para resolver as situações-problema "de cabeça" ou se podia usar calculadora. Ao ler o primeiro problema, comentou:

Bia: Esse problema é muito confuso para minha cabeça.

Joyce: Eu subtraio ou não?

Pesquisadora: O que vocês acham que devemos fazer? Por que seria uma subtração? Por que você está desmanchando? [Dirigindo-se à Bia.]

Bia: Porque não é de menos. Se você perguntou, é porque não deve ser.

Então, propus às alunas que lêssemos o problema novamente para que analisassem cada um dos passos apresentados na ficha de apoio. Depois de verificar passo a passo, as alunas concluíram que o problema envolvia uma adição e não uma subtração, como pensaram inicialmente.

Bia: Nossa! Ainda bem que só nós estamos aqui. Estou com vergonha, parecia fácil.

Ao discutir o $2^{\circ}$ problema, Bia ficou em dúvida sobre o resultado de sua adição, pois havia encontrado um valor diferente do de sua colega e começou a desmanchar sua resolução.

Pesquisadora: Por que você está desmanchando sua atividade?

Bia: Uai? Porque está errado. Então fui para o quadro e com o auxílio das colegas resolvi o problema [expressão de espanto]. Estava certo e eu desmanchei! [Diário de campo, 27/07/17.]

Durante nossos encontros, Bia relatou dificuldade para aprender Matemática diversas vezes. Logo no início desse episódio, a aluna expressou sua dificuldade, ao comentar: "Esse problema é muito confuso para minha cabeça". Durante as aulas de Matemática, a aluna usualmente conferia os resultados

\footnotetext{
${ }^{8}$ Denominamos entrevistas informais as conversas realizadas em momentos variados com uma ou algumas das alunas participantes do grupo de estudos, ao longo dos encontros. 
encontrados na resolução de suas atividades com os de seus colegas e, no momento da correção das tarefas, também costumava desmanchar com muita frequência o que havia escrito em seu caderno.

Ainda no episódio retratado, ao ser questionada sobre o que fazer para resolver o problema, a aluna vai logo desmanchando sua resolução, antes de qualquer observação negativa ou questionamento sobre a mesma. Momentos depois, ao constatar um resultado diferente do encontrado pela colega, repete a ação. Porém, após a correção, percebe que tinha resolvido corretamente a tarefa e se espanta com o sucesso.

A autoeficácia é um julgamento de recursos específicos para a realização da tarefa e baseiase nos sucessos e fracassos (LINNENBRINK; PINTRICH, 2002). A ausência de sucesso, repetidamente, pode levar os alunos à descrença em sua própria capacidade. Conjecturamos que, talvez, Bia estivesse habituada a fracassar na realização de tarefas de Matemática ao longo de sua vida escolar, por isso, desmanchou as atividades antes que fossem corrigidas.

Além disso, o costume de apagar os resultados, antes mesmo de saber se estavam certos ou errados, sinaliza que Bia antecipa resultados ruins. A antecipação é uma característica básica da agência humana. Eventos futuros não podem ser causas da motivação, contudo, por serem representados cognitivamente no presente, "são convertidos em motivadores e reguladores do comportamento no presente” (BANDURA, 2008, p. 75). Ao que parece, Bia antecipava que seus resultados estavam errados, talvez guiada por crenças de autoeficácia frágeis, e os apagava.

A aluna também manifestou sentir vergonha diante do fato de não conseguir desenvolver corretamente um problema que julgava ser fácil, e ressaltou que se sentia melhor com a participação de poucos alunos por encontro, pois evitava constrangimentos.

Outra situação que observamos foi o receio de algumas das discentes quanto à habilidade para a futura prática docente. Presenciamos momentos nos quais elas manifestavam medo ou dúvidas em relação à própria capacidade de ensinar.

Nos dois primeiros horários do dia 09/06/2017, discutimos o capítulo quatro do livro de Constance Kamii. Um aluno comentou que, do livro todo, esse era o capítulo de que mais havia gostado, porque nele a autora apresentava sugestões de como trabalhar com os números na prática. Aproveitando o comentário tecido pelo aluno, Karol disse: "Eu ainda tenho muito medo de não saber ensinar Matemática na sala de aula... É muito difícill" [Trecho do diário de campo: aula do dia 09/06/17.]

Karol parecia apreensiva diante da ideia de lecionar Matemática e atribuía a dificuldade à situação. Em algumas atividades do grupo de estudos, a licencianda afirmou que, embora apresentasse boas notas nas avaliações, a Matemática não era sua disciplina preferida. Também comentou que não tinha facilidade para aprender essa disciplina. Tais percepções, comuns no grupo, evidenciam como as experiências prévias dos indivíduos são uma das fontes de maior influência na construção da autoeficácia (AZZI e POLYDORO, 2010).

Acreditamos que o fato de não ter muita afinidade com a Matemática e ter dificuldade para aprendê-la possam ter influenciado diretamente a percepção de Karol sobre sua crença acerca da própria capacidade para aprender e ensinar essa disciplina.

Bia também se mostrava receosa quanto à futura prática docente. Nos trechos a seguir, apresentamos duas situações nas quais ela questiona a própria capacidade de ensinar os conteúdos explorados na disciplina, e de se tornar uma boa professora de Matemática.

A primeira você já me explicou que era sobre esse negócio de desagrupar. Na verdade, eu tinha olhado o de Lúcia para tentar fazer. Mas não tinha entendido. Não sei também fazer muito bem o algoritmo da divisão com dois ou mais números. Eu decorei, sabe? Mas não sei explicar. Tem hora que eu penso: será que eu vou dar conta de ensinar isso para as crianças? Eu sei que isso não cai na prova de agora. Mas está me atormentando. [Diário de campo, 07/08/17].

No encontro do dia 30/10/17, ao verificar que não estava conseguindo realizar as dobras para modelar a fração, Bia se questionou se conseguiria ser uma boa "professora de Matemática". 
Bia: Gente, será que não vou ser boa professora de Matemática? Eu não estou conseguindo fazer as dobras direitinho.

Lúcia: Mas vai melhorar. E pode ser uma boa professora sem saber dobrar direitinho [risos].

Pesquisadora: Quantas partes azuis são necessárias para obter uma amarela?

Clara: 2.

Pesquisadora: E quantas partes verdes são necessárias para obter uma amarela? E uma azul?

Clara: 4 e 2.

Pesquisadora: Quantas partes vermelhas são necessárias para obter uma amarela? E uma azul? E uma verde?

Bia: 8 para vermelha, 4 para azul e 2 para verde.

Lúcia: Arrasou! Depois fala que não vai ser boa professora, viu? Você sabe! [Diário de campo, 30/10/17].

Podemos perceber em ambas as situações que, ao buscar apoio no grupo para sanar suas dificuldades, Bia foi acolhida. Sua atitude sugere que ela considerou que o apoio do grupo fosse algo que pudesse levá-la a ao sucesso. Em concordância com os resultados encontrados por Torisu (2010), acreditamos que isso só foi possível porque a aluna se sentiu confortável no ambiente do grupo de estudos, pois "o ambiente de ajuda mútua, não hostil, gera uma sensação de conforto, facilitando o processo de ensino e aprendizagem" (TORISU, 2010, p. 102). Tal situação também parece corroborar os resultados do estudo de Ross (1995, apud BZUNECK, 2000). Ao analisar as influências positivas da colaboração entre professores dentro da escola (e podemos pensar que nossos sujeitos eram professores), o autor concluiu que os professores melhoram suas crenças de autoeficácia porque as ajudas que recebem de seus colegas contribuem para melhorar, progressivamente, suas habilidades de ensino e o domínio dos conteúdos. As crenças de autoeficácia, nesse caso, acabam por assumir um caráter coletivo (BZUNECK, 2000).

Destacamos, também, o apoio que Bia recebeu de Lúcia. Esta última incentivou a colega por meio de comentários que a fizessem sentir-se confiante. Esses comentários, de caráter incentivador, são conhecidos, na Teoria Social cognitiva, como persuasão verbal, uma importante fonte de autoeficácia (PAJARES; OLAZ, 2008).

Assim como os colegas de classe, os professores também podem influenciar as crenças de seus alunos, por meio da persuasão verbal. Por meio de comentários encorajadores, os professores podem despertar sentimentos de segurança em seus alunos, levando-os a construir crenças de autoeficácia mais robustas. Da mesma forma, críticas severas e não construtivas podem desestimular os alunos e deixá-los desanimados e inseguros.

Com o passar do tempo, começamos a observar, entre as participantes, indícios de maior confiança em sua capacidade para aprender Matemática. No episódio a seguir, por exemplo, apresentamos as percepções de Maria, Teresa e Karol sobre a atividade diagnóstica que iniciou o estudo de frações.

Pesquisadora: Começamos neste semestre a trabalhar com frações. Gostaria de saber o que vocês acharam daquelas atividades diagnósticas da aula de Matemática e como se sentiram neste nosso início de semestre.

Maria: Eu fiquei com um pouco de medo.

Teresa: Fração, eu acho que vou me dar bem. Espero que esse período seja mais tranquilo.

Maria: Gente, eu lembro que eu gostava de Matemática. Eu ia bem em tudo até a sétima série. Mas eu gostei das tarefas da atividade diagnóstica, apesar que eu vi que não sei muita coisa.

Pesquisadora: Aqui eu tenho uma barra de chocolate. E nós vamos dividir essa barra entre nós. [Distribuí um pedaço de chocolate para cada uma das alunas.] O pedaço que você ganhou representa que parte da barra de chocolate?

Teresa: Quantos pedaços tem a barra toda? [Olhando para a barra.]

Pesquisadora: Vamos ver? [Mostro o restante da barra e Teresa conta os pedacinhos.] Teresa: 20 pedaços no total. 
Maria: O meu representa 6 alguma coisa 20. Não sei como fala. Porque um terço, dois quartos é fácil.

Pesquisadora: Mas, se você fosse representar no caderno, como faria?

Maria: 6/20. [Lê: seis vinte.]

Pesquisadora: Nós lemos esta fração assim: 6/20. [Lê: seis vinte avos.]

Maria: Ah, tá! era esse avos. Sabia que tinha isso em fração, mas nem lembrava como usar.

Comentei com as alunas que, para compreendermos o que é uma fração, temos que entender bem o que é a unidade. E que, no caso do chocolate, a fração representa a parte sobre o todo. Que temos que lembrar que a fração representa um único número, o número fracionário. Após a atividade, entreguei para elas tiras de papéis coloridas todas do mesmo tamanho, 30. Pedi que as dividissem ao meio. Quando elas terminaram de dividir, perguntei: Existe somente uma forma de dividir essa tira de papel ao meio? (...)

Maria: E o $2 / 2$ ? Eu às vezes não entendo esses assim? (...)

Teresa: É um todo.

Maria: Ah, tá. O inteiro. É isso. Tudo é o inteiro que é $1.5 / 5,20 / 20$, tudo é 1.

Teresa: Dá para simplificar. Depois nós vamos explorar a simplificação e equivalência melhor.

Pesquisadora: Isso aí. [Grupo de estudos, 05/10/17.]

Maria afirmou não se sentir confiante em relação à própria capacidade para resolver as atividades propostas pelo professor, pois percebeu que não se recordava dos conteúdos abordados. Já Teresa, ao resolver as atividades, avaliou que poderia obter melhor desempenho nesse tema, uma vez que possuía certa facilidade para trabalhar com as frações, e, provavelmente por essa razão, acreditou que poderia "se sair bem". Maria, apesar do receio quanto ao novo conteúdo, participou ativamente no encontro, respondendo às questões propostas pela pesquisadora e esclarecendo suas dúvidas, sugerindo que a aluna acreditava que seu empenho e dedicação poderiam levá-la a compreender o tema estudado.

Tais cenários evidenciam que, quando os indivíduos acreditam que as suas ações podem levá-los a alcançar o resultado que desejam, eles têm incentivo para agir e superar as dificuldades (AZZI e POLYDORO, 2010). E, por outro lado, quando não se sentem assim, as emoções que predominam são medo e receio de não ser capaz de realizar as tarefas propostas.

Outra característica interessante da situação descrita são as estratégias autorregulatórias de aprendizagem apresentadas pelas estudantes. Segundo Zimmerman, Bonner e Kovach (2002, apud AZZI; POLYDORO, 2008), a autorregulação acadêmica refere-se aos pensamentos, sentimentos e ações aplicados para atingir objetivos educacionais específicos e envolve, dentre outros processos, a identificação, planejamento e implementação de estratégias para resolver problemas. Se observarmos as falas de Maria, Teresa e Karol, retiradas do diálogo travado durante a atividade com frações,

Maria: Dá para dobrar assim também [dobrando o papel na horizontal].

Teresa: Tem. Se a gente fizer um triângulo assim [mostrando a dobra na diagonal].

Teresa: Dá para simplificar. Depois nós vamos explorar a simplificação e equivalência melhor. Maria: Podia multiplicar cruzado?

Karol: Se eu contar tudo?

Teresa: Uai? Peguei o 24 e formei 4 grupos. Depois eu tomei 3 deles. Se a gente contar dá para achar 18.

Karol: Por isso a gente faz então, divide pelo de baixo e multiplica pelo de cima. [Grupo de estudos, 05/10/1.]

percebemos que as estudantes estavam propondo estratégias para resolver as questões que surgiam ou eram postas pela pesquisadora, ou seja, em alguma medida, estavam agindo de forma autorregulada. Mais que isso, o fato de proporem estratégias é evidência de um encorajamento para expor suas ideias que talvez tenha surgido da maior credibilidade em suas capacidades, ou seja, sua autoeficácia. Caso suas estratégias para resolver os problemas fossem adotadas com resultados satisfatórios, as estudantes poderiam vivenciar experiências de êxito, importantes fontes de autoeficácia. Isso nos mostra 
que autorregulação e autoeficácia se influenciam mutuamente. Para Zimmerman e Cleary (2006, apud AZZI; POLYDORO, 2008, p. 158):

a autoeficácia interfere na autorregulação porque está associada à antecipação, seleção e preparação para a ação. Por sua vez e de modo recíproco, a autorregulação influencia a crença de autoeficácia, ao fornecer informações sobre o progresso, esforço e tempo despendido na realização da atividade, participando de sua construção.

No encontro do grupo de estudos do dia 31/10/2017, discutimos frações impróprias e números mistos. Após desenvolver algumas tarefas planejadas para explorar esses temas, Karol perguntou: "podemos refazer a questão 4 que o professor deu na sala? Eu não entendi muito bem, mas acho que agora, se eu pegar, vou entender melhor".

Karol realizou corretamente as tarefas propostas durante o encontro do grupo de estudos e participou das discussões sobre as atividades com as colegas. Neste momento, propôs que retomássemos a questão 4, realizada anteriormente, em classe. Esse comportamento corrobora a ideia de que "uma pessoa que experimenta bons resultados tende a fortalecer sua crença de autoeficácia e elevar suas expectativas em relação àquela situação e outras semelhantes" (AZZI e POLYDORO, 2010, p. 130). Também reforça os resultados encontrados por Torisu (2010), que evidenciaram que as experiências de êxito que os alunos vivenciavam inicialmente criavam uma situação de conforto e de confiança em si mesmos para persistir em tarefas posteriores. Acreditamos que as situações de êxito vivenciadas por Karol, durante o encontro, permitiram que ela se sentisse confiante para desenvolver a questão que o professor havia trabalhado na aula e que, até então, não havia compreendido.

No dia 12/12/17, durante encontro do grupo de estudos, após discutirmos algumas de suas dúvidas sobre Geometria, Bia mostrou-se confiante para ir ao quadro durante a aula de Matemática. Porém, o comportamento da aluna não era esse no início desse mesmo encontro. Vejamos alguns comentários feitos por ela e por suas colegas, durante a discussão dos conteúdos.

Bia: O pior é que o professor já marcou a prova. Ele disse que vai ser em dupla, mas eu estou sem jeito porque estou com medo de não saber contribuir com meu par.

Lúcia: Acho que tem muita gente na sala que está "boiando". Ninguém está falando nada, mas acho que ninguém não está compreendendo tão bem assim não.

Bia: Mas a gente tem que aprender isso. Como é que vou ensinar isso se eu não aprender?

Clara: Gente, isso aprende em que série? Parece que eu pulei isso na escola.

Lúcia: Bia, sei o que a gente pode fazer. Vamos desenhar esses poliedros.

As alunas Bia e Lúcia, durante a explicação, desenharam vários poliedros.

Bia: Não acredito! Estou começando a entender. Que lindo! Ju, pergunta às meninas. Eu estava tão chateada na aula de sexta. O professor me chamou para participar lá no quadro e eu não fui. Ele falou que me ajudava, mas como não estava entendendo nada, fiquei com muito medo de errar. Mas, se me chamar essa semana, eu vou! [Grupo de estudos, 12/12/17]

Bia tinha dúvidas sobre os nomes dos sólidos e suas características. Sentia-se apreensiva, por acreditar que não teria condições de colaborar com sua colega na realização da atividade avaliativa que se aproximava. Suas colegas também pareciam receosas em relação ao novo conteúdo. Torisu (2010) aponta, com base nos estudos de Pajares e Olaz (2008), que alunos que duvidam de suas habilidades acadêmicas preveem notas baixas, antes mesmo de realizarem as avaliações. Por ter dúvidas sobre os conteúdos apresentados, Bia tinha receio de não saber contribuir com seu par, o que provavelmente, além de expor sua fragilidade quanto ao domínio de conteúdo, poderia implicar um resultado negativo para a dupla na avaliação.

Nesse encontro do grupo de estudos, com o intuito de apoiá-las, retomei os assuntos discutidos pelo professor nas aulas, procurando trabalhar as dúvidas apresentadas pelas estudantes. Ao final do encontro, Bia pareceu satisfeita por compreender os conteúdos lecionados, e até se dispôs a ir ao quadro na próxima aula de Matemática. Isso corrobora a ideia de que os indivíduos tendem a se 
engajar em tarefas nas quais se sentem mais confiantes e competentes, e tendem a evitar aquelas nas quais não se sentem capaz (AZZI e POLYDORO, 2010).

Quanto maior a percepção de autoeficácia matemática, maior o esforço e a persistência. Consequentemente, a autoeficácia também influencia as escolhas feitas pela pessoa e suas ações. Foi a partir da percepção de sua autoeficácia matemática (considerar-se capaz para resolver a atividade) que Bia mudou o curso de sua ação (ir ao quadro).

Outras situações nas quais as alunas se manifestaram mais seguras de sua capacidade de ensinar foram observadas ao longo dos encontros no grupo de estudos.

Bia: Eu tenho dúvida na Matemática inteira. Ainda bem que nós estamos participando do grupo de estudos e estamos tendo apoio nas aulas. Vou ser boa professora.

Lúcia: Seremos. [Grupo de estudos, 06/11/17]

Durante as aulas de Matemática e nos encontros iniciais do grupo de estudos, Bia se questionava sobre sua futura prática docente, tendo em vista suas dificuldades com os conteúdos estudados. Porém, nesse fragmento do diário de campo, observamos que ela se mostrou confiante sobre a possibilidade de ser uma boa professora, apesar de reconhecer que ainda tem dúvidas sobre alguns conteúdos matemáticos.

Ao final do estudo, na resposta à pergunta 4c do questionário (proposto em 18/01/2018), tanto Bia quanto outras colegas, participantes do grupo de estudos, manifestam mais autoconfiança em relação à própria capacidade para aprender e, inclusive, pare ensinar Matemática.

Questão 4) Você concorda com as ideias expressas abaixo? Explique sua resposta:

c) Hoje, acredito que sou capaz de ensinar vários conteúdos de Matemática para as crianças dos anos iniciais.

Clara: Acredito ser capaz de ensinar a Matemática, devido como as aulas são ministradas, temos que realizar atividade e pensar como se estivéssemos dando aula, por isso fica mais fácil saber como ministrar uma aula de Matemática.

Alice: Ainda não sou capaz, mas tenho certeza de que com o minicurso'serei.

Duda: Sim. O grupo de estudos proporcionou uma maior interação, além da oportunidade ser fundamental para aprimorar o aprendizado.

Bia: Vários não. Mas grande parte do que aprendi na disciplina nesse semestre e no semestre passado, sim. Justamente pela forma que nos foi passado o conteúdo. Além de preocuparem com o nosso aprendizado, fizeram de tudo para compreendermos a melhor forma de trabalhar isso com nossos futuros alunos.

Karol: Sim. Se eu revisá-los, eu sei que sou capaz.

Lúcia: Sim, porque com o minicurso percebi que com empenho e criatividade a Matemática se torna muito mais interessante e desafiadora.

Teresa: Sim, agora não me vejo perdida como antes. Imaginava que de todas as matérias, Matemática seria aquela que eu nunca entenderia, muito menos ensinaria. Mas hoje, graças aos encontros (os quais sou imensamente grata), sei que sou capaz de ensinar de fato meus alunos e não simplesmente passar conteúdos. Há muitas formas de fazer as crianças se apaixonarem e contextualizarem a Matemática em suas vidas, agora sei disso. Maria: Sim. Os materiais fornecidos (...) e as atividades realizadas me proporcionaram maior segurança com relação ao ensino de Matemática.

Clara, Duda, Karol, Lúcia, Teresa e Maria se percebem capazes de ensinar vários conteúdos de Matemática para as crianças dos anos iniciais. Suas respostas sugerem que a participação no grupo de estudos foi importante para o fortalecimento da crença na própria capacidade de aprender e ensinar Matemática.

\footnotetext{
${ }^{9}$ Algumas alunas utilizavam o termo minicurso para se referir ao grupo de estudos. Acreditamos que isso talvez se deva ao fato de associarem as tarefas realizadas às situações de minicurso e não de aula.

Educação em Revista|Belo Horizonte|v.36|e227158|2020
} 
Bia, entretanto, menciona que ainda não se sente confiante para ensinar outros conteúdos. Como nos apontam Linnenbrink e Pintrich (2002), Rodrigues (2015), presume-se que a autoeficácia seja situada e contextualizada. Por exemplo, um estudante, dependendo de seus sucessos e fracassos, pode ter crenças de autoeficácia diferentes para resolver problemas envolvendo conteúdos diferentes.

Situação similar acontece com Alice:

Vou ser sincera. O que eu vi depois que entrei no grupo de estudo eu lembro, eu acho que dou conta de ensinar. Mas é porque aqui tem atendimento personalizado [risos]. Aí, acho que eu concentro mais e não fico com medo de falar bobeira. [Grupo de estudos, 27/11/17]

Alice também afirmou se considerar capaz de ensinar os conteúdos que aprendeu, durante os encontros do grupo de estudos, porém, em resposta à questão 4c do questionário, percebemos que a aluna ainda se sente insegura para realizar tal tarefa. Ao serem questionadas sobre como se sentiam quando um conteúdo matemático era ensinado, a maioria das alunas assinalou as alternativas (b) e (c), indicando que acreditavam que, contando com o apoio do grupo e/ou concentrando-se na tarefa ("se prestar atenção e me esforçar muito"), seriam capazes de aprender.

A alternativa (b) atribui a capacidade para aprender ao esforço e à atenção destinada à execução da tarefa. Já a alternativa (c) aponta o auxílio do grupo como recurso fundamental para a aprendizagem. Embora a ajuda do grupo possa ser considerada uma causa externa, acreditamos que ela seja um elemento propulsor para o envolvimento das alunas nas tarefas, o que pode ser o primeiro passo rumo à motivação para aprender. Notamos também que, com exceção de Duda e Maria, todas as alunas que assinalaram a alternativa (c) também assinalaram a (b), o que já mostra a percepção de uma causa interna para sua aprendizagem, que é o próprio esforço. 'Tendo em vista a relação inicial das alunas com a Matemática, principalmente nas aulas, tais respostas trazem fortes indícios de uma mobilização das crenças de autoeficácia matemática, pois, apesar de ainda considerarem-na como uma disciplina difícil, já se percebem capazes de aprendê-la.

Tais ideias são corroboradas pela entrevista realizada mais adiante $(29 / 01 / 18)$ :

Teresa: Hoje eu me sinto capaz de aprender Matemática porque diferente do ensino médio, eu tenho mais confiança em mim mesma e isso me faz acreditar que sou capaz (...).

Duda: (...) Hoje eu acho que sou capaz de aprender e de ensinar também, os conteúdos para o Ensino Fundamental, claro [risos].

Karol: (...) Não sou tão ruim em Matemática. Não odeio, mas também não gosto. Mas me considero, acho que sou capaz de aprender os conteúdos (...). [Trechos da entrevista, 29/01/2018]

As alunas demonstram certa confiança para aprender, diferente do que observamos nos relatos iniciais dos nossos encontros no grupo de estudos. Ao longo de nossa pesquisa, percebemos que algumas delas, como Teresa, por exemplo, durante a formação na Educação Básica, não alcançavam um bom desempenho na disciplina e se sentiam desanimadas com a aprendizagem de Matemática. Mesmo não tendo tanta afinidade com a disciplina, como aponta Carol, percebemos que elas se veem capazes de aprender os conteúdos matemáticos e até mesmo de ensiná-los, como destaca Duda.

Os dados produzidos ao longo do estudo evidenciam indícios de fortalecimento das crenças de autoeficácia por todas as participantes do grupo de estudos. Todas se mostraram mais confiantes em relação à própria capacidade de ensinar e de aprender. Tais resultados foram provenientes, dentre outras coisas, das experiências de sucesso vivenciadas ao longo dos encontros do grupo e nas aulas de Matemática.

Acreditamos que o fato de se sentir capaz de aprender tenha influenciado o comportamento das alunas, durante a execução das tarefas, seja no grupo de estudos ou nas aulas de Matemática. Como Bzuneck (2009b, p. 118), entendemos que "um aluno motiva-se a envolver-se nas atividades de aprendizagem caso acredite que, com seus conhecimentos, talentos e habilidades, poderá adquirir novos conhecimentos, dominar um conteúdo, melhorar suas habilidades". Assim, os dados da presente pesquisa evidenciam que a motivação para aprender Matemática foi significativamente influenciada pelo fortalecimento das crenças de autoeficácia matemática. 
Como já abordado em nosso referencial teórico, a autoeficácia matemática e a aprendizagem dessa disciplina estão interligadas. As percepções de autoeficácia matemática dos estudantes podem ser consideradas tanto como um motivo para aprender, como consequência das tentativas de aprendizagem (SCHUNK, 1984, 1989, apud ZIMMERMAN, 2010). Ao avaliar seu desempenho nas tarefas, os resultados alcançados podem deixar o aluno otimista e confiante em suas potencialidades, da mesma forma que, ao se sentir capaz, o aluno pode ficar mais entusiasmado para desenvolver a tarefa. Alunos com crenças de autoeficácia matemática mais robustas tendem a ser mais persistentes, empregam maior esforço para a realização bem-sucedida das tarefas e se sentem mais motivados para atingir as metas estabelecidas (TORISU e FERREIRA, 2009; PAJARES e OLAZ, 2008).

Porém, temos ciência de que as crenças de autoeficácia são necessárias para a motivação, mas não são suficientes, pois não são o único fator motivacional e nem constituem um fator que atua de modo isolado no processo da motivação para aprender (BZUNECK, 2009b com base em SCHUNK, 1991). Logo, entendemos que aspectos como a dinâmica das atividades do grupo, o clima de respeito e colaboração que se estabeleceu, dentre outros, também podem ter contribuído para este resultado.

\section{CONSIDERAÇÕES FINAIS}

Neste artigo, nos propusemos a discutir possíveis relações entre as crenças de autoeficácia matemática e a motivação para aprender essa disciplina por parte de um grupo de licenciandas em Pedagogia que participaram de um grupo de estudos ao longo de mais de um semestre.

Ao longo dos encontros do grupo de estudos, priorizamos a construção de tarefas que proporcionassem às alunas oportunidades de refletirem sobre sua aprendizagem matemática e sua prática docente futura. Buscamos, ainda, apresentar algumas estratégias de aprendizagem autorregulada, para que elas se tornassem mais autônomas durante seus estudos. Tal dinâmica foi construída com objetivo de propiciar momentos em que elas se sentissem mais encorajadas a participar e a esclarecer suas dúvidas com relação aos conteúdos matemáticos abordados. Tudo isso em um ambiente respeitoso e amigável, no qual podiam se sentir seguras e apoiadas.

No início do estudo, observamos que as participantes não possuíam uma autoeficácia matemática robusta, pelo contrário, se sentiam inseguras em relação à própria capacidade de aprender essa disciplina. A maioria delas não tinha lembranças positivas com relação à aprendizagem de Matemática nos anos anteriores ao ingresso na faculdade. Foram comuns, durante os encontros, relatos de situações que demonstravam insatisfação com a própria aprendizagem e, até mesmo, com a falta de compreensão sobre os conteúdos já estudados na Educação Básica. E era evidente sua preocupação com a futura prática docente, sobretudo com o ensino de Matemática.

Ao longo dos encontros do grupo, observamos que elas começaram a se expressar mais acerca das próprias dúvidas, a se alegrar com cada pequena vitória (por exemplo, ao solucionar corretamente um problema) e a se apoiarem mutuamente. Cada uma delas, a seu modo, experimentou de forma particular as vivências proporcionadas nos encontros e se desenvolveu.

Ao analisar a mobilização das crenças de autoeficácia das alunas, verificamos que ela esteve associada às vivências possibilitadas pela participação no grupo de estudos. Além de se tornarem mais confiantes em relação a sua capacidade de aprender e de ensinar, as experiências de sucesso vivenciadas por elas foram determinantes. Como a literatura destaca, êxitos continuados informam ao aluno que ele pode ser capaz de executar novas tarefas, o que, por sua vez, proporciona a informação convincente de que é capaz de prosseguir com sucesso (SCHUNK, 1989 apud BZUNECK, 2009b). A vivência de situações de sucesso permitiu que as alunas se tornassem mais confiantes em sua capacidade, e isso as incentivou a participar nas atividades, visando à obtenção de novos sucessos. Além disso, conforme nos aponta Bzuneck (2009b), os julgamentos de autoeficácia de uma pessoa determinam seu nível de motivação, pois, em função desses julgamentos, a pessoa tem incentivo para agir, e imprime suas ações para alcançar os resultados projetados.

As evidências apresentadas no presente artigo sugerem que o fortalecimento da autoeficácia matemática também influenciou a motivação para aprender das participantes do grupo de estudos. Ao experimentarem sucesso em várias tarefas gradativamente mais exigentes, começaram a se perceber 
capazes de aprender Matemática e se motivaram a aprender essa disciplina. Por sua vez, estando mais motivadas a aprender, se empenhavam mais nas tarefas e obtinham melhores resultados, gerando um círculo virtuoso. Paralelamente, o desenvolvimento de algumas estratégias de autorregulação, aprendidas nos encontros do grupo de estudos, também favoreceu o fortalecimento da autoeficácia matemática.

Estudantes autorregulados possuem crença de autoeficácia mais robustas, interesse intrínseco nas tarefas, são mais persistentes e possuem maiores chances de atingir o sucesso (ZIMMERMAN, 2010). A autorregulação oferece ao aluno informações sobre seu progresso e atuação no processo de aprendizagem, o que influenciará sua motivação e confiança em sua capacidade. Ao mesmo tempo, as suas crenças de autoeficácia lhe ajudarão a selecionar estratégias para desenvolver as tarefas e superar desafios.

Em síntese, o grupo de estudos, tanto pelo espaço de convivência respeitosa e colaborativa, quanto pela dinâmica voltada para a aprendizagem matemática em uma perspectiva autorregulada, favoreceu o desenvolvimento de crenças de autoeficácia matemática mais positivas entre as participantes e a motivação para aprender essa disciplina.

Iniciativas mais duradouras e abrangendo um número maior de futuros professores dos Anos Iniciais do Ensino Fundamental podem promover importantes mudanças relacionadas às crenças, atitudes e relação estabelecida com a Matemática, influenciando, assim, de modo positivo, a aprendizagem matemática e a aprendizagem matemática para a docência dos envolvidos.

Nesse sentido, diversas questões e possibilidades se descortinam. Em que medida estamos formando nossos futuros professores para aprender Matemática, apreciar essa disciplina e acreditar na própria capacidade de aprender e solucionar problemas matemáticos? Em que medida conseguimos preparar esses futuros profissionais para ensinar Matemática de forma que as crianças se sintam motivadas para aprender, confiantes na própria capacidade e autorreguladas em relação à sua aprendizagem? Refletir sobre tais questões pode mobilizar esforços no sentido de se repensar a formação matemática oferecida aos futuros pedagogos, de modo a pensar neles primeiro como aprendizes que precisam se desenvolver emocional e cognitivamente, que precisam se sentir motivados para aprender e capazes de autorregular sua aprendizagem, para, então, construirmos possibilidades de ensino e aprendizagem da Matemática na Escola Básica.

\section{REFERÊNCIAS}

AZZI, R. G; POLYDORO S. A. J. Autorregulação: aspectos introdutórios. In: BANDURA, A; AZZI, R. G.; POLYDORO, S. Teoria Social Cognitiva: conceitos básicos. Porto Alegre: Artmed, 2008, p. $149-164$.

O papel da autoeficácia e autorregulação no processo motivacional. In:

BORUCHOVITCH, E.; BZUNECK, J. A.; GUIMARÃES, S.E.R. (Orgs.). Motivação para aprender: Aplicações no contexto educativo. Petrópolis: Vozes, 2010. p. 126-144.

BANDURA, A. A teoria social cognitiva na perspectiva da agência. In: BANDURA, A; AZZI, R. G.; POLYDORO, S. Teoria Social Cognitiva: conceitos básicos. Porto Alegre: Artmed, 2008, p. 69 - 96.

BAUMANN, A. P. P.; BICUDO; M. A. V. Cursos de Pedagogia e de Matemática formando professores de matemática para os anos iniciais do Ensino Fundamental: em busca de uma compreensão. Zetetiké: Revista de Educação Matemática, Campinas, SP, v. 18, n. 34, p. 181- 204, jul./dez. 2010.

BRASIL, Resolução CNE/CP n. ${ }^{\circ}$ 1, de 15 de maio de 2006. Diário Oficial da União: seção 1, Brasília, DF, p.11, 16 de maio de 2006.

Disponível em:http://portal.mec.gov.br/cne/arquivos/pdf/rcp01_06.pdf. Acessoem: 20 jun. 2016. 
BROPHY, J. Syntesis of Researh on strategies for Motivating Students to Learn. Educational Leadership, v.45, n.2, p.40 - 48, out. 1987.

Disponívelem:http://www.ascd.org/ASCD/pdf/journals/ed_lead/el_198710_brophy.pdf. Acesso em: 25 jul. 2016.

BZUNECK, J. A. As crenças de auto-eficácia dos professores. In: SISTO, F. F., OLIVEIRA, G. de; FINI, L. D. T. (Orgs.). Leituras de psicologia para formação de professores. Petrópolis: Vozes, 2000, p. 115-134.

A motivação do aluno aspectos introdutórios. In: BORUCHOVITCH E.

BZUNECK J.A (Orgs.). A motivação do aluno: contribuições da psicologia contemporânea. 4. ed. Petrópolis: Vozes, 2009a, p.9-36.

As crenças de autoeficácia e seu papel na motivação do aluno. In: BORUCHOVITCH E. BZUNECK J.A (Orgs.). A motivação do aluno: contribuições da psicologia contemporânea. 4.ed. Petrópolis: Vozes, 2009b, p.116-133.

CAZORLA, I. M. SANTANA, E. R. dos S.. Concepções, atitudes e crenças em relação à Matemática na formação do professor da Educação Básica. In: Reunião Anual da ANPED, 28, 2005, CaxambuMG. Anais [...]. Caxambu: ANPED, 2005. Disponível em:

http://www.ufrrj.br/emanped/paginas/conteudo_producoes/docs_28/concepcoes.pdf. Acesso em: 25 maio 2018.

FERREIRA, Enizete Andrade. Autoeficácia e satisfação no trabalho de docentes-alunos do PARFOR, 2018. Dissertação (Mestrado em Educação) - Programa de Pós-Graduação em Educação, Universidade Federal do Pará, Belém, 2018. Disponível em:

http://ppgedufpa.com.br/arquivos/File/ENIZETE.pdf. Acesso em: 19 jun 2019.

FIORENTINI, Dario. A pesquisa e as práticas de formação de professores de matemática em face das políticas públicas no Brasil. Bolema, Rio Claro, v. 21, n. 29, p. 43-70, 2008. Disponível em: http://www.redalyc.org/pdf/2912/291221870004.pdf. Acessoem: 25 maio 2018.

LINNENBRINK, E. A.; PINTRICH, P.R. Motivation as an enabler for academic success. School Psychology Review, Cuyahoga Falls, v. 31, n. 3, p. 313-327, 2002. Disponível em: http:// citeseerx.ist.psu.edu/viewdoc/download;jsessionid=9A5565183E0F7FE47CFFCE5E9D92F94 7?doi=10.1.1.520.1534\&rep=rep1\&type=pdf. Acesso em: 05 ago. 2016.

MINAYO, M.C.S. O desafio da pesquisa social. In: MINAYO, M.C.S (Org.); DESLANDES S. F.; GOMES, R.; Pesquisa social: teoria, método e criatividade. Petrópolis, RJ: Vozes, 2009a, p.9-29.

PAJARES, F. e OLAZ, F. Teoria Social Cognitiva e autoeficácia: uma visão geral. In: BANDURA, A; AZZI, R. G.; POLYDORO, S. Teoria Social Cognitiva: conceitos básicos. Porto Alegre: Artmed, 2008, p. 97-114.

REEVE, J. Motivação e Emoção. Tradução Luís Antônio Fajardo e Stella Machado. 4.ed. Rio de Janeiro: LTC, 2011.

RODRIGUES, Carolina Soares. Crenças de autoeficácia matemática na Educação de Jovens e Adultos: um estudo com alunos do ensino médio de Divinópolis (MG).Dissertação (Mestrado Profissional em Educação Matemática) - Programa de Pós Graduação em Educação Matemática, Universidade Federal de Ouro Preto, Ouro Preto, 2015. Disponível em:

https://www.ppgedmat.ufop.br/arquivos/dissertacoes_2015/Carolina\%20Soares\%20Rodrigues\%20di ssertacao\%20final.pdf. Acesso em: 20 jul. 2016.

SOUTO, Nayara Mariano. Percepções de futuros pedagogos acerca de sua formação matemática: estudo com licenciados de dois cursos de Pedagogia de Minas Gerais. Dissertação 
(Mestrado em Educação) - Programa de Pós-Graduação em Educação, Universidade Federal de Ouro Preto, Ouro Preto, 2016. Disponível em: http://www.repositorio.ufop.br/handle/123456789/7108. Acesso em: 20 maio2016.

TANURI, Leonor Maria. História da formação de professores. Revista Brasileira de Educação, Ago 2000, no.14, p.61-88. Disponível em: http://www.scielo.br/cgi-bin/wxis.exe/iah/. Acesso: 19 abr. 2020.

TOLENTINO, Jucileide das Dores Lucas. Investigando a motivação para aprender Matemática no curso de Licenciatura em Pedagogia: análise de um grupo de estudos. Dissertação (Mestrado Profissional em Educação Matemática) - Programa de Pós Graduação em Educação Matemática, Universidade Federal de Ouro Preto, Ouro Preto, 2018. Disponível em:

http://www.ppgedmat.ufop.br/index.php/producao/dissertacoes). Acesso em: 10 jun 2019.

TORISU, E. M.; FERREIRA, A. C. A teoria social cognitiva e o ensino-aprendizagem da matemática: considerações sobre as crenças de autoeficácia matemática. Ciências \& Cognição, Rio de Janeiro, v. 4, n. 3, p. 168-177, 2009. Disponível em:

https://www.repositorio.ufop.br/bitstream/123456789/4658/1/ARTIGO_TeoriaSocialCognitiva.pdf. Acesso em: 19 jun. 2019.

TORISU, Edmilson Minoru. Crenças de auto-eficácia e Motivação para a Matemática: um estudo com alunos do Ensino Fundamental de uma escola pública de Ouro Branco/MG.

Dissertação (Mestrado Profissional em Educação Matemática) - Programa de Pós Graduação em Educação Matemática, Universidade Federal de Ouro Preto, Ouro Preto, 2010. Disponível em: https://www.repositorio.ufop.br/bitstream/123456789/2532/1/DISSERTA\%C3\%87\%C3\%83O_Cr en\%C3\%A7asAutoEfic\%C3\%A1cia.pdf. Acesso em: 25 fev. 2016.

ZIMMERMAN, B. J. Self-Regulated Learning and Academic Achievement: An Overview.

EducationalPsychologist, v.25, n.1, p.3-17, 2010. Disponível em:

$<$ https://ciel.viu.ca/sites/default/files/self_regulated_learning_and_academic_achievement_an_overvi ew_0.pdf>. Acesso em 18 de jan. de 2017.

Submetido: $07 / 08 / 2019$

Aprovado: 15/06/2020 